\title{
CLINICAL, SOME EPIDEMIOLOGICAL AND RISK FACTORS STUDIES OF COENUROSIS IN SHEEP AT DAKAHLIA GOVERNORATE, EGYPT
}

\author{
MOHAMED A. EL BESKAWY ${ }^{1}$; SAMAR M. ATWA ${ }^{1}$; IBRAHEIM A. ABBAS ${ }^{2}$ and \\ EMMAN A. ABOELFADL ${ }^{3}$ \\ ${ }^{1}$ Department of Internal Medicine, Infectious Diseases and Fish Diseases. Faculty of Veterinary \\ Medicine, Mansoura University, Egypt. Fax: 0020502379952 \\ ${ }^{2}$ Department Parasitology, Faculty of Veterinary Medicine, Mansoura University, Egypt. \\ ${ }^{3}$ Department of Animal Husbandry, Faculty of Veterinary Medicine, Mansoura University, Egypt.
}

Received: 31 March 2018; Accepted: 24 April 2018

\begin{abstract}
This study was carried on 747 sheep located in Dakahlia Governorate, Delta region, Egypt, over one year (March 2014 to February 2015). Out of them 43 sheep showed different nervous signs. The diseased sheep were incised and examined for the presence of Coenurus cerebralis cysts to study the clinical, risk factors, and some epidemiological pattern of coenurosis. Brain samples from 43 diseased sheep from four localities in Dakahlia Governorate were collected. The various nervous clinical signs of coenurosis were presented in variant degrees regarding to the affected site and location of the coenurus cyst. The clinical manifestation represented by head tilting $42 \%$, head pressing $3.48 \%$, dropping of ears $49 \%$, circling $70 \%$, blindness $16 \%$, recumbencey $30 \%$, and posterior paralysis $11.53 \%$. The relationship between the site of coenurus cyst and the manifested clinical signs could help in predicting the location of the cyst from the clinical signs for further interference specially in case of valuable animals. A significant correlation was detected between prevalence of coenurosis, rearing system, availability of dogs \& fox and locality at P-values $<(0.019,0.019$ and 0.044 , respectively).The risk factors and epidemiological patterns could help in developing control measures.
\end{abstract}

Key words: Coenurus cerebralis, epidemiology, risk factors, sheep, Egypt.

\section{INTRODUCTION}

Coenurosis is a fatal disease of sheep and goats caused by $T$. Multiceps which is characterized by nervous manifestations including circling, blindness, head deviation and mortalities (Njau et al., 1988, Biyikoglu et al., 1998 and EL Beskawy et al., 2016) the economic impacts of this disease were a significant (Bussell et al., 1997 and Achenef et al., 1999).

Coenurus cerebralis is the metacestode of the tapeworm Taenia multiceps. Domestic and wild canids constitute the predators, while a wide range of herbivores, including small and large ruminants, yak and equines are the prey hosts, (Sharma and Chauhan 2006). This parasite usually inhabits the central nervous system specially the left and right cerebral hemispheres of herbivores. (Desouky et al., 2011).

Corresponding author: Dr. MOHAMED A. EL BESKAWY E-mail address: melbeskawy@gmail.com

Present address: Department of Internal Medicine, Infectious Diseases and Fish Diseases. Faculty of Veterinary Medicine, Mansoura University, Egypt.
The prevalence of sheep coeneurosis was reported in many countries like in Iran $(9.8 \%)$ Oryan et al. (1994), in Turkey (1.3\%) Akkaya and Vurusaner, 1998; in Jordon (3\%) Abo-Shehada et al. (2002); in Italy $(0.35 \%)$ Scala et al. (2007); and (5\%) in Brazilain sheep (Gazioglu et al., 2017), and in Egypt overall infection rate was (3.03\%) Amer et al. (2017) and $(2.3 \%)$ (EL Beskawy et al., 2016) and $C$. cerebralis cysts were found in $(3.7 \%)$ out of the examined sheep of the involved sheep population. (Abbas and EL Beskawy 2016).

This study was aimed primarily to investigate the most common risk factors associated with occurrence of coenurosis in different geographical regions of Dakahlia Governorate, Egypt. Further more the relationship between site of coenurosis cyst and the manifested clinical signs of diseased animals.

\section{MATERIALS AND METHODS}

\section{1- Studied area}

Dakahlia Governorate, is about 3459 kilometers square located in the northeast of the delta region, Egypt, has a large number of animals specially sheep (119850 heads). Sheep flocks in these localities were varied in their numbers from sixty to up to one 
hundred per flock, Table (1) and Fig.(1), but all of them participate the same regimen of grazing as semi-fixed flocks. The migratory nature of these flocks from place to place, rendered them in contact with other flocks and sometimes with wild animals

Questionnaire includes the different risk factors as age, sex, circling radius (wide or narrow), disposal of offal by (burning, burrier, in water canals, or introduction to dogs within the flocks), contact with dogs and other carnivores as foxes, periodic treatment of in contact dogs, the site of the cyst in the cerebrum, cerebellum or spinal cord and the type of rearing (inside or outside doors), were fully discussed.

\section{2- Animals}

From March 2014 to February 2015, 747 sheep located in Dakahlia Governorate, Delta region, Egypt, were examined according to (Constable et al., 2017) 43 animals showed different nervous signs which were recorded. The diseased animals were slaughtered and postmortem exanimation were done according to (Harris 1998).

\section{3- Samples collection}

Forty three brain samples were obtained after palpation and incision of brains from 43 diseased sheep showing typical nervous signs of coeneurosis allover one year (March 2014 to February 2015). Identification and examination of cysts were done in Parasitology Department, Faculty of Veterinary Medicine, Mansoura University, Egypt, All procedures were approved by the Ethical Committee for Animal Experiments, Mansoura University, Egypt.

\section{4- Statistical analysis}

Data analysis were performed using SPSS version 16.0 (SPSS). Difference in occurrence of clinical signs according to cyst site (cerebrum and cerebellum) were statistically evaluated using (crosstabs) Chi-square test to compare their distribution. The chi-squared test was used to determine whether there was a significant difference between the expected frequencies and the observed frequencies in our outcomes. Also, non parametric correlation test (Kendall's tau-b and Spearman's rho correlation tests were used to test the relation between disposal of offals, prevalence of cysts and (age, sex, locality, type of rearing and presence of $\operatorname{dogs} \&$ fox). It assesses how well the relationship between variables can be described using a monotonic function. SPSS, (2004).

\section{RESULTS}

Forty three sheep out of 747 sheep in four localities, showed different nervous signs by clinical examination (Table 1). The various nervous signs were head tilting $42 \%$, dropping of ears $49 \%$, circling $70 \%$, blindness $16 \%$ and recumbency $30 \%$, (Table $2 \&$ Figs.2-8). Twenty six out of 43 diseased sheep showed Coenurus Cerebralis. cyst, revealed prevalence of $3.48 \%$. The cysts was located in the cerebral hemispheres, and the cerebellum (Figs 914).

The frequency of coenurosis in different localities was $42.33 \%, 19.23 \%, 23.07 \%$, and $15.38 \%$ for Belkas, Mansoura, Dikrnis and Aga respectively, (Table 3). Furthermore, it was $30.76 \%$ and $69.23 \%$ for male and female respectively, in addition to the site of the cyst, the frequency of coenurosis was $80.76 \%$ for cerebrum and $19.23 \%$ for cerebellum, while rearing system as outdoor rearing was presented by $61.53 \%$ and indoors was $38.46 \%$ (Table $3)$.

A highly significant difference in the distribution of cysts was detected in wide circling and narrow circling and it was high in the cerebrum in a wide circling, but it was high in cerebellum in case of narrow circling and no significant difference were detected in other signs due to the effect of the cyst (Table 4).

A significant correlation was detected between prevalence of cysts and (rearing system, availability of dogs \& fox and locality) at P-value $(0.019,0.019$ and 0.044 , respectively table (5).

Table 1: Area of study and numbers of samples:

\begin{tabular}{ccc}
\hline Area & $\begin{array}{c}\text { Total number Of examined } \\
\text { sheep }\end{array}$ & Number of sheep showing nervous \\
signs
\end{tabular}


Table 2: percentage of different clinical signs of coenurosis infected sheep.

\begin{tabular}{ccc}
\hline Clinical signs & $\begin{array}{c}\text { No. of Coenurosis infected sheep } \\
\text { Total No. (26) }\end{array}$ & Percent $(\%)$ \\
\hline Head tilting & 18 & $42 \%$ \\
\hline Head pressing & 1 & $3.84 \%$ \\
\hline Dropping of ears & 21 & $49 \%$ \\
\hline Circling & 22 & $\mathbf{7 0 \%}$ \\
\hline Blindness & 7 & $16 \%$ \\
\hline Recumbencey & 13 & $30 \%$ \\
\hline Posterior paralysis & 3 & $11.53 \%$ \\
\hline
\end{tabular}

Table 3: Presence of Coenurosis infected sheep according to locality, sex, location of the cyst, age and breeding system.

\begin{tabular}{|c|c|c|c|}
\hline Items & Criteria & Frequency $($ No. $=26)$ & Percent \\
\hline \multirow{4}{*}{ localty } & Belkas & 11 & $42.33 \%$ \\
\hline & Mansoura & 5 & $19.23 \%$ \\
\hline & Dikirnis & 6 & $23.07 \%$ \\
\hline & Aga & 4 & $15.38 \%$ \\
\hline \multirow{2}{*}{$\operatorname{sex}$} & male & 8 & $30.76 \%$ \\
\hline & female & 18 & $69.23 \%$ \\
\hline \multirow{2}{*}{ Location of cyst } & cerebrum & 21 & $80.76 \%$ \\
\hline & cerebellum & 5 & $19.23 \%$ \\
\hline \multirow{2}{*}{ Rearing system } & Outdoors & 16 & $61.53 \%$ \\
\hline & indoors & 10 & $38.46 \%$ \\
\hline \multirow{4}{*}{ Age } & $0-3$ months & 0.0 & $0.0 \%$ \\
\hline & 4 Months -1 year & 11 & $42.33 \%$ \\
\hline & $>1$ year -2 years & 6 & $23.07 \%$ \\
\hline & $>2$ years & 9 & $34.61 \%$ \\
\hline
\end{tabular}

Table 4: The effect of location of the cyst and outcome of different clinical signs.

\begin{tabular}{llll}
\hline Cyst location & Chi- Value & df & P-value \\
\hline Location of cysts * Head tilting & 0.434 & 1 & $0.510^{\text {N.S }}$ \\
\hline Location of cysts * Wide circling & 20.63 & 1 & $0.000^{* *}$ \\
\hline Location of cysts * Narrow circling & 26.00 & 1 & $0.000^{* *}$ \\
\hline Location of cysts *Head pressing & 0.248 & 1 & $0.619^{\text {N.S }}$ \\
\hline Location of cysts * Dropping ears & 2.23 & 1 & $0.135^{\text {N.S }}$ \\
\hline Location of cysts * Posterior paralysis & 4.91 & 1 & $0.085^{\text {N.S }}$ \\
\hline Location of cysts * blindness & 1.47 & 1 & $0.225^{\text {N.S }}$ \\
\hline Location of cysts * recumbency & 0.516 & 1 & $0.473^{\text {N.S }}$ \\
\hline
\end{tabular}

A highly significant difference in the distribution of cysts were detected in wide circling and narrow circling and it was high in cerebrum in wide circling but it was high in cerebellum in case of narrow circling and no significant difference were detected in other signs due to the effect of the cyst. 
Table 5: Different risk factors affecting prevalence of coenurosis infected sheep.

\begin{tabular}{ccc}
\hline Bivariate correlation & Kendall's tau-b & Spearman's rho correlation \\
\hline Prevalence of coenurosis*presence of dogs & $-0.243(\mathrm{p}<0.148)^{\mathrm{N.S}}$ & $-0.289(\mathrm{p}<0.152)^{\mathrm{N.S}}$ \\
\hline Prevalence of coenurosis *removal of disposal & $-0.195(\mathrm{P}<0.255)^{\mathrm{N} . \mathrm{S}}$ & $-0.232(\mathrm{p}<0.264)^{\mathrm{N.S}}$ \\
\hline Prevalence of coenurosis * type of rearing & $0.395(\mathrm{p}<0.019)^{*}$ & $0.470(\mathrm{p}<0.015)^{*}$ \\
\hline Prevalence of coenurosis *availability of dogs\&fox & $-0.393(\mathrm{p}<0.019)^{*}$ & $-0.468(\mathrm{p}<0.016)^{*}$ \\
\hline Prevalence of coenurosis *age & $0.218(\mathrm{p}<0.156)^{\mathrm{N.S}}$ & $0.286(\mathrm{p}<0.156)^{\mathrm{N.S}}$ \\
\hline Prevalence of coenurosis *sex & $0.332(\mathrm{p}<0.048)^{\mathrm{N.S}}$ & $0.395(\mathrm{p}<0.046)^{\mathrm{N.S}}$ \\
\hline Prevalence of coenurosis *locality & $0.312(\mathrm{p}<0.044)^{*}$ & $0.413(\mathrm{p}<0.036)^{*}$ \\
\hline
\end{tabular}

A significant correlation was detected between prevalence of cysts and (rearing system, availability of dogs $\&$ fox and locality) at $\mathrm{P}$-value $<(0.019,0.019$ and 0.044 , respectively)
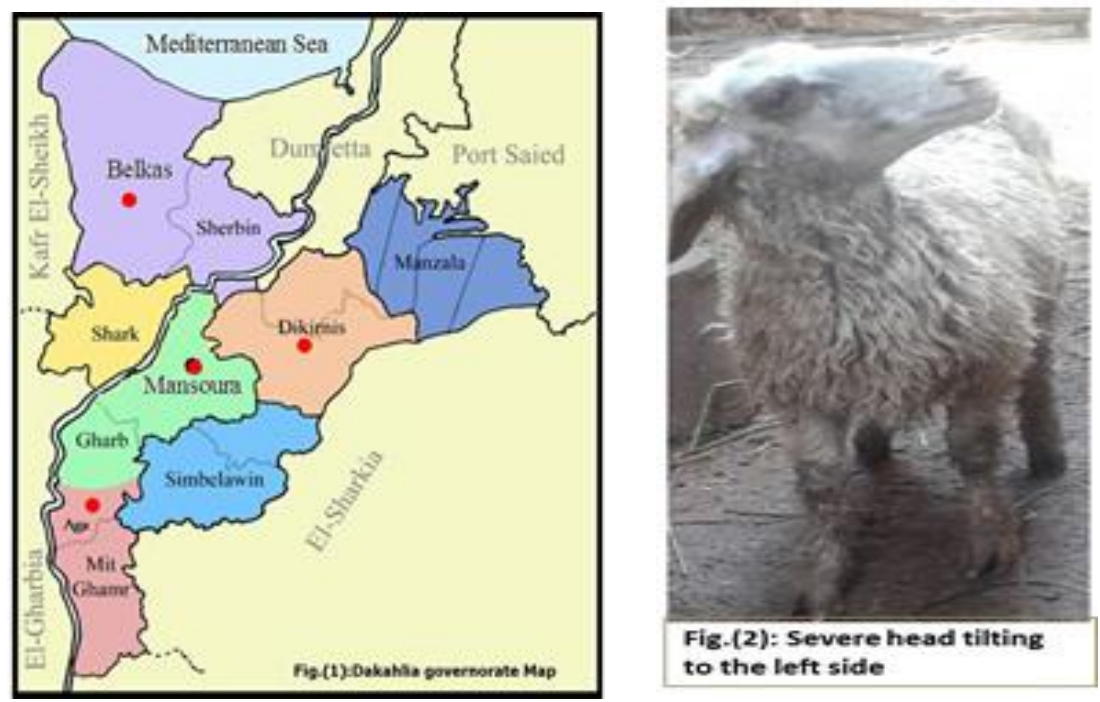

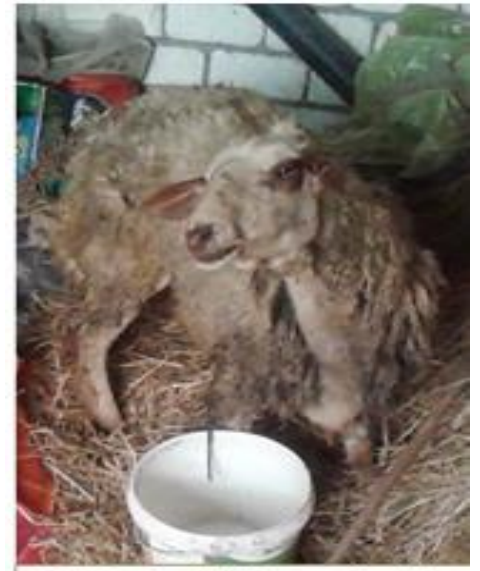

Fig. (3): head tilting to the right side

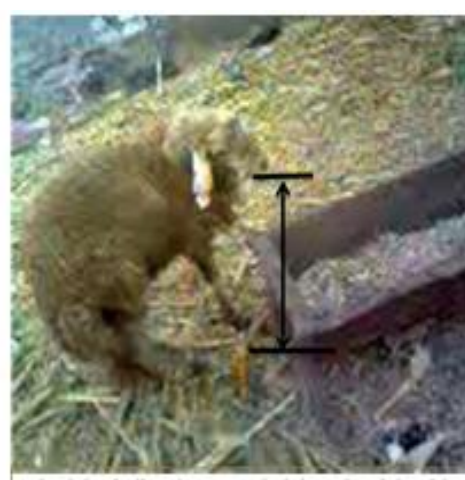

Fig. (6): Circling (narrow circle) to the right side

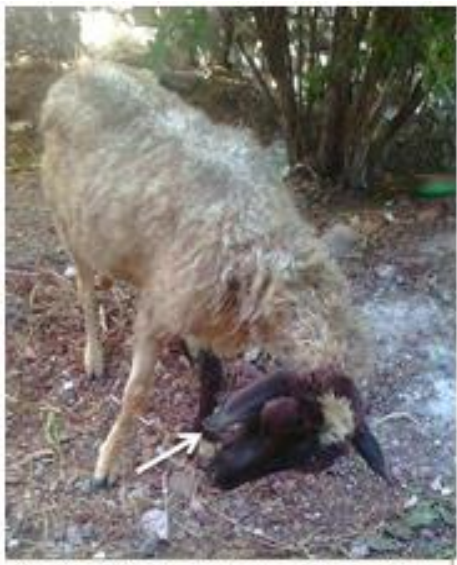

Fig. (4): twisting of neck and tilting of the head to the right side, dropped right ear

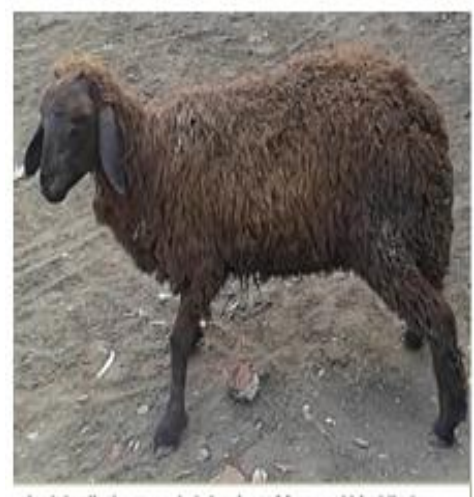

Fig. (7): Blindness and abduction of fore and hind limbs

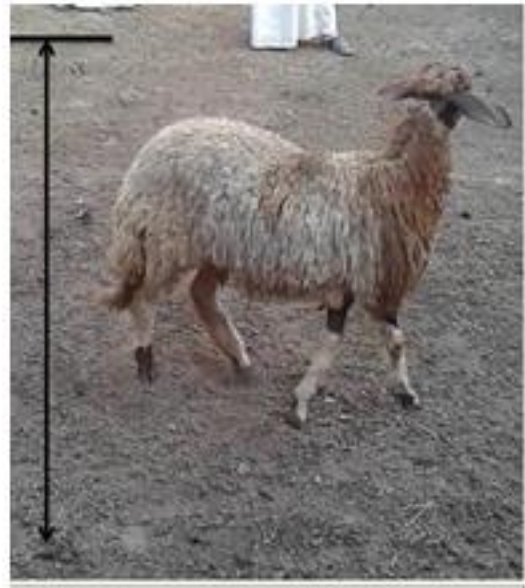

Fig. (5): Circling (wide circle) to the left side

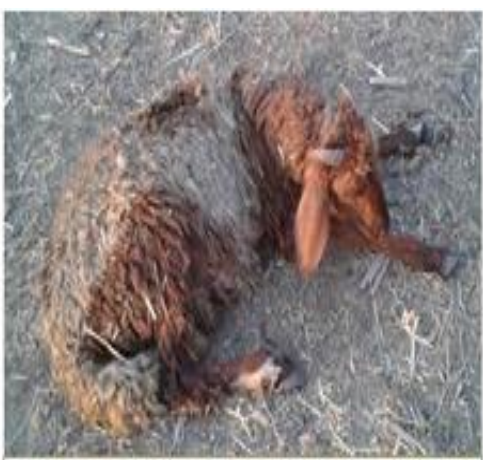

Fig. (8): Recumbencey and inability for standing 


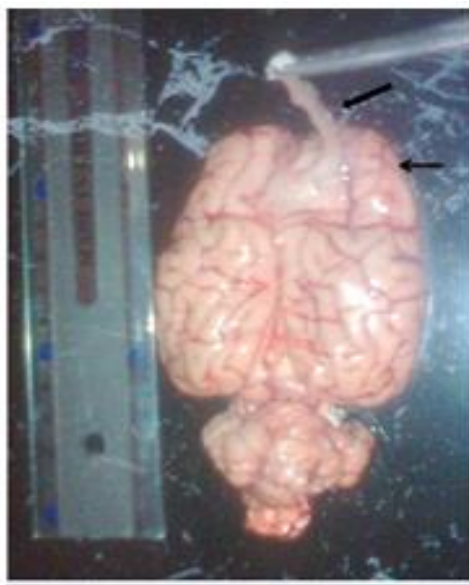

Fig. (9): C . Cerebralis cyst (thick arrow), Aight frontal lobe (thin arrow) sheep brain

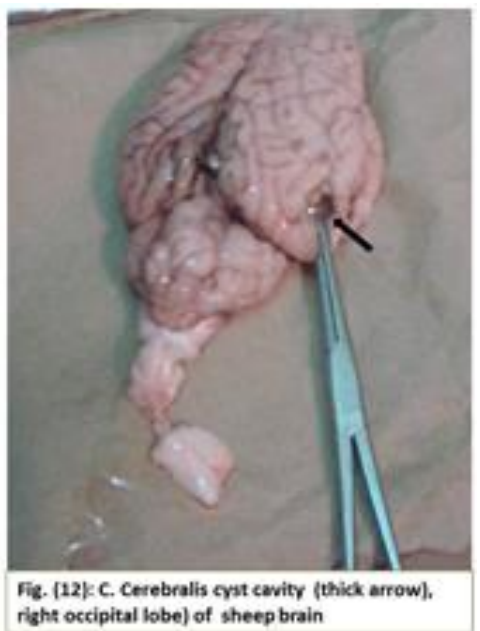

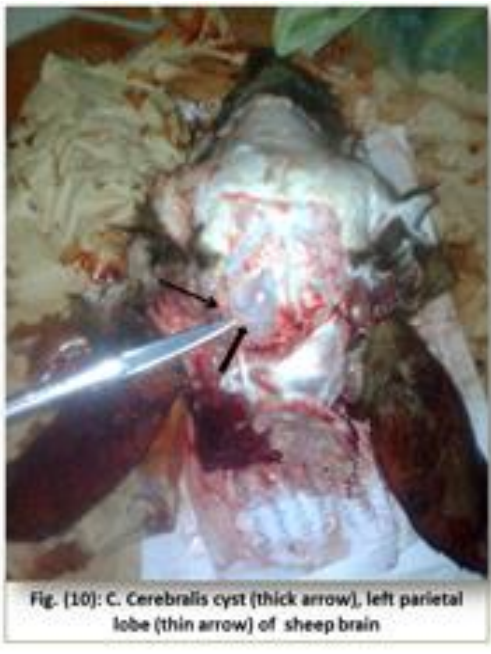

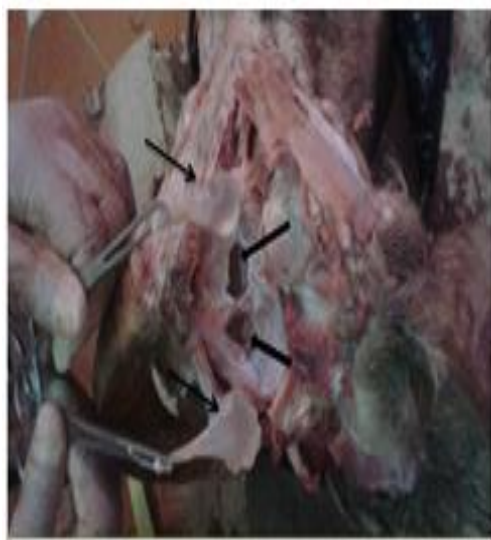

Fiq. (13):Two C. Cerebrals osts (thin arrow), Formed avitites (thick arrows) left parietal lobe of sheep brin
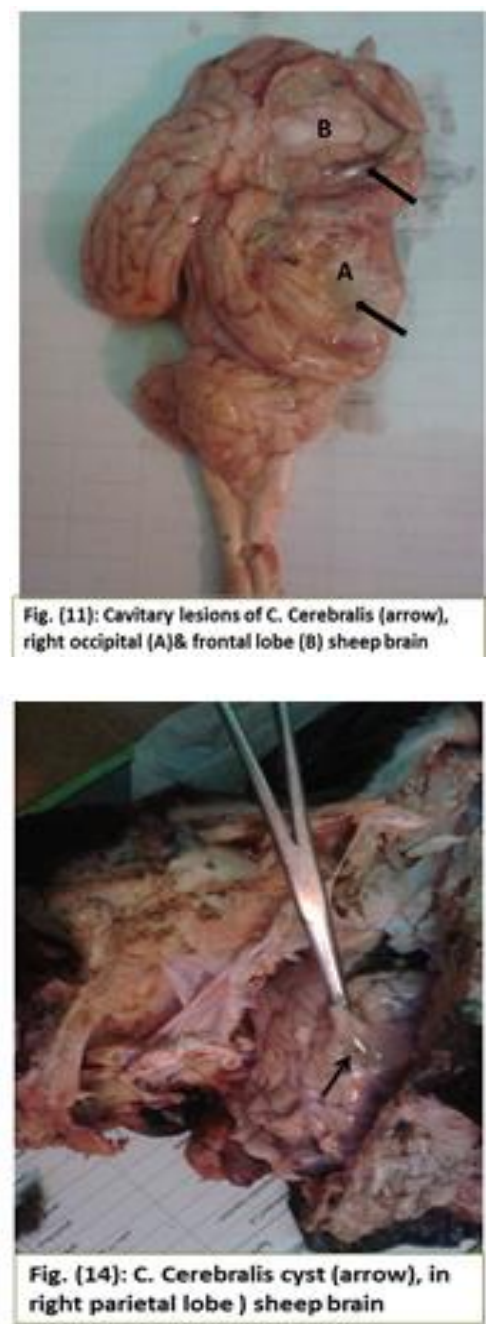

\section{DISCUSSION}

Coenurosis is a serious disease responsible for high economic losses in the sheep industry, in addition to its zoonotic impact. Coenurus Cerebralis considered as the principal cause for nervous manifestations of sheep and goats in Egypt, (Desouky et al., 2011).

The overall prevalence of coenurosis in this study was $(3.48 \%)$ as 26 generates sheep out of 747 total previously examined sheep, in Egypt, Coenurus Cerebralis intermediate stage of $T$. Multiceps infection was estimated at $18.3 \%$ in sheep flock from Suez Canal province (Desouky et al., 2011, Anwar et al., 2013) reported $100 \%$ prevalence in clinically diseased sheep from Cairo, although they did not find any cysts in the apparently healthy animals. Globally, different occurrences were recorded, $44.4 \%$ in Tanzania (Mira et al., 2015), $100 \%$ and $2.7 \%$ from clinically diseased and apparently healthy sheep, respectively from 7.3\% in Iraq (Karim 1979), Ethiopia (Achenef et al., 1999), 3\% in Jordon (AboShehada et al., 2002), 0.35\% in Italy (Scala et al., 2007), 15.5\% in Turkey (Gicik et al., 2007) and $18.7 \%$ in Iran (Tavassoli et al., 2012), The variations in the prevalence in different geographical zones might be attributed to the varied geographical, sociological and ecological factors (Sharma and Chauhan 2006).

The various nervous clinical signs of coenurosis were presented in varying degrees according to the affected site of the brain and site of the coenurus cyst either in the cerebrum or cerebellum, Table (2) and Figs. (214)., (Abo- Shehada et al., 2002) the severity of clinical signs attributed to the inflammatory response of the animal, the site of the cyst, and the number of the ingested viable T. Multiceps eggs (Edwards, and Herbert, 1982).

Recognition of risk factors affecting the prevalence of coenurosis, the locality had a clear role as shown in Table (3) Belkas was the highest in frequency of coenurosis (42.33\%), and Aga was the lowest (15.38\%), A significant correlation was detected between prevalence of coenurosis and locality at Pvalue $<0.044$, Table (5) this was due to the open borders of Belkas and availability to stray dogs, foxes, and in contact with other travelling flocks during feeding on the stumps of the crops after harvesting season. 
The risk of sex on prevalence of coenurosis was noticed as females were higher in prevalence in comparison to males Table (3) as males usually kept for meat consumption only and usually sold for fattening while females always kept for breeding, the chance for a females to be infected by coenurosis is higher than males, this is in parallel with that of Karim (1979).

Age remains an important risk factor for coenurosis, as age group started from 4 months up to 1 year was the highest $42.33 \%$ Table (3) these results were in agreement with that of (Achenef et al., 1999) who reported that susceptible age of sheep to coenurosis ranged from 6 to 24 months and (Abo-Shehada et al., 2002) who reported a prevalence rate of $10 \%$ of coenurus cysts in the age group six months to 2.5 years.. While age group $0-3$ months was $0.0 \%$ at this age had little chance of infection with coenurosis due to their feeding habits, the long incubation period and maternal immunity (Sharma and Chauhan 2006).

The rearing system as a risk factor for occurrence of coenurosis was clear in sheep reared outdoors was higher in prevalence of coenurosis than that kept indoors Table (3), there was a significant correlation between prevalence of coenurosis and rearing system, at a $\mathrm{P}$ - value $<0.019$, Table (5), this due to the fact that outdoors, sheep were in contact with other infected flocks, stray dogs, contaminated pastures by the feces of dogs and other carnivores, also, a significant correlation was detected between prevalence of coenurosis and availability of dogs (present within the flocks or stray) \& foxes at P-value $<0.019$ Table (5) in contact with sheep.

Prevalence of coenurosis within the cerebral cyst was higher $(80.76 \%)$ than coenurosis within cerebellar cyst (19.23\%), Table (3) this was in accordance with that of (Achenef et al., 1999) as he reported $96 \%$ for cerebral coenurosis and $4 \%$ for cerebellar coenurosis. The relationship between the location of the coenurus cyst and the circling was clear as there was a highly significant difference in the distribution of cysts in wide circling and narrow circling. It was high in cerebrum in wide circling but it was high in cerebellum in case of narrow circling and no significant difference were detected in other signs due to the site of the cyst either in cerebrum or cerebellum. Table (4).

In this study, In spite of non significant correlation between prevalence of coenurosis, and disposal of offals of sheep to dogs, it is very important to put in mind that preventing offals of sheep to reach dogs or foxes is a critical point in preventing coenurosis in sheep specially when there is no, treatment regimens for dogs.

\section{CONCLUSION}

The rearing system, locality, age, sex of sheep, the presence of dogs specially none treated with contact with sheep are considered as the major risk factors for occurrence of coenurosis in sheep flocks.

The clinical picture of the coenurosis manifested differently according to the site of the cyst (cerebrum or cerebellum) in the brain especially with the circling radius could help in predicting the location of the cyst from the clinical signs for further interference specially in case of valuable animals.

\section{ACKNOWLEDGEMENT}

The authors would like to thank Prof. Dr. Mohamed Ibraheim Eissa Prof. of Infectious Diseases, Faculty of Veterinary Medicine, Zagazig University for his kind help in revising the manuscript.

\section{AUTHOR'S CONTRIBUTION}

Mohamed EL beskawy designed and carried out the wok, sample collection and wrote the article, Samar Atwa shared in sample collection and writing the article Emman Aboelfadl, carried out the statistical analysis, I., Abbas, diagnosed and identified the coenurus cyst, all authors wrote and approved the final manuscript.

\section{REFERENCES}

Abbas, I. and El Beskawy, M. (2016): Molecular and Phylogenetic Status of Coenurus cerebralis Infecting Sheep from Dakahlia Province, Egypt, The Journal of Advances in Parasitology, 3,(4) 117-124.

Abo-Shehada, M.N.; Jebreen, E.; Arab, B.; Mukbel, $R$. and Torgerson, P. (2002): Prevalence of Taenia multiceps in sheep in northern Jordan. Prev. Vet. Med; 55: 201-202.

Achenef, M.; Makos, T.; Feseha, G.; Hibert, A. and Tembely, S. (1999): Coenurus cerebralis infection in Ethiopian Highland sheep: Incidence and observations on pathogenesis and clinical signs. Trop. Anim. Health Prod; 33 (1): 15-24.

Akkaya, H. and Vurusaner, C. (1998): Coenuriasis cerebralis in sheep and Calves Slaughtered in Istanbul. Acta Parasitol Turcica, 22(3): 320324.

Amer. S.; Ahmed ElKhatam; Yasuhiro Fukuda; Lamia I. Bakr; Shereif Zidan; Ahmed Elsify; Mostafa A. Mohamed; Chika Tada and Yutaka Nakai (2017): Prevalence and Identity of Taenia multiceps cysts "Coenurus cerebralis" in Sheep in Egypt. Acta Tropica 176, December 2017, Pages 270-27

Anwar, S.; Mahdy, E.; El-Nesr, K.A.; El-Dakhly, K.M.; Shalaby, A. and Yanai, T. (2013): Monitoring of parasitic cysts in the brains of a flock of sheep in Egypt. Rev. Bras. Parasitol. Vet., 22 (3): 323-330.

Benifla, M.; Barrelly, R.; Shelef, I.; El-On, J.; Cohen, A. and Cagnano, E. (2007): Huge hemispheric intraparenchymal cyst caused by Taenia 
multiceps in a child. Case report. J. Neurosurg; 107 (6): 511-514.

Biyikoglu, G. and Doganay, A. (1998): Effects of praziquntel and albendazole on Coenurus cerebralis in experimentally infected lambs. Turk Veterinerlik ve Hayvancilik Dergisi 22 (1): 43-48.

Bussell, K.M.; Kender, A.E. and Scott, P.R. (1997): Posterior paralysis in a lamb caused by a Coenurus cerebralis cyst in the lumbar spinal cord. Vet. Rec; 140: 560.

Constable D. Peter; Kenneth W. Hinchcliff; Stanely H. Done and Walter GR-nberg (2017): Veterinary Medecine: A text book of the diseases of Cattle, Horses, Sheep, Pigs and Goats, Eleventh Edition, 3251 Riverport Lane, St. Louis, Missouri 63043

Desouky, E.A.; Badawy, A.I. and Refaat, R.A. (2011): Survey on coenurosis in sheep and goats in Egypt. Veterinaria Italiana, 47 (3): 333-340.

Edwards, G.T. and Herbert, V. (1982): Observation on the course of Taenia multiceps infections in sheep: clinical signs and post-mortem findings. Brit. Vet. J. 138, 489-500.

El-beskawy, M.A.; Mohamed El-Adl; Mohamed Hamed; Mayar Ali and Moustafa Al-Araby (2016): Myelin Basic Protein is DownRegulated in Sheep Affected with Ovine Coenurosis. Alexandria Journal of Veterinary Sciences, Oct. 51 (1): 198-206.

Gazioglu, A.; Sami Simsek; Omer Kizil; Ali Osman Ceribasi; Harun Kaya Kesik and Haroon Ahmed (2017): Clinical, pathological and molecular evaluations and CT scan screening of coenurosis (Coenurus cerebralis) in sheep and calves. Braz. J. Vet. Parasitol., Jaboticabal, v. 26, n. 1, p. 3-9.

Glcık, Y.; Kara, M. and Arslan, M.O. (2007): Prevalence of Coenurus cerebralis in sheep in Kars Province, Turkey. Bull. Vet. Inst. Pulawy 51: 379-382.
Harris, H.E. (1998): Veterinary pathology, 4th Edition Oxford, unipress, New York, Torento.

Inechukwu, B.I. and Onwukeme, K.E. (1991): Intraocular coenurosis: a case report. Br. J. Opthalmol; 75 (7): 430-431.

Karim, M.A. (1979): A survey of coenurosis in sheep in Northern Iraq. Trop. Anim. Hlth. and Prod., 11(1): 157-158.

Miran, M.B.; Nzalawahe, J.; Kassuku, A.A. and Swai, E.S. (2015): Prevalence of coenurosis in sheep and goats at three slaughter slabs in Ngorongoro District, Tanzania. Trop. Anim. Health Prod., 47(8): 1591-1597.

Njau, B.C.; Kasali, O.B.; Scholtens, R.G. and Mesfin, D. (1988): Review of sheep mortality in Ethiopian highlands (ILCA Bulletin No. 31, AddisAbaba, Ethiopia): 19-22. (cited by Achenef, M; Markos, T; Feescha, G; Hibret, A. and Tembley, S. (1999): Coenurus cerebralis infection in Ethiopian highland sheep: incidence and observations on pathogenesis and clinical signs. Trop. Anim. Health Prod; 33 (1): 15-24.

Oryan, A.; Moghaddar, N. and Gaur, S.N.S. (1994): Metacestodes of sheep with special reference to their epidemiological status, pathogenesis and economic implications in Fars Province Iran. Vet. Parasitol; 51 (3-4): 231-240.

Scala, A.; Cancedda, G.M.; Varcasia, A.; Ligios, C.; Garippa, G. and Genchi, C. (2007): A survey of Taenia multiceps coenurosis in Sardinian sheep. Vet. Parasitol., 143 (3-4): 294-298.

Sharma, D.K. and Chauhan, P.P.S. (2006): Coenurosis status in Afro-Asian region: A review. Small ruminant research, 64: 197-202.

SPSS (2004): Statistical Package for Social Sciences. Release 16.0 versions. SPSS Inc. USA.

Tavassoli, M.; Malekifard, F.; Soleimanzadeh, A. and Tajik, H. (2012): Prevalence of Coenurus cerebralis in sheep in Northwest of Iran. Vet. Res. Forum, 2: 274-276

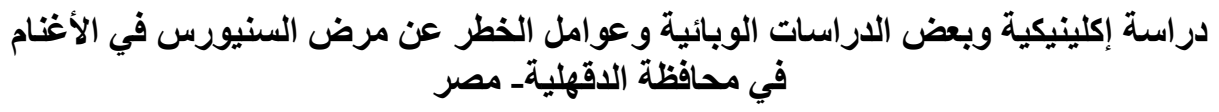

$$
\text { محد البسكاوى ، سمر عطوة ، إبراهيم عباس ، إبيان أبب الفضل }
$$

E-mail: melbeskawy@gmail.com Assiut University web-site: www.aun.edu.eg

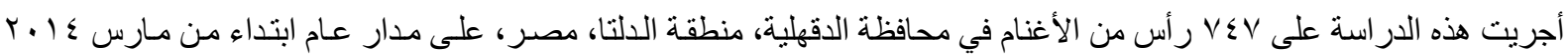

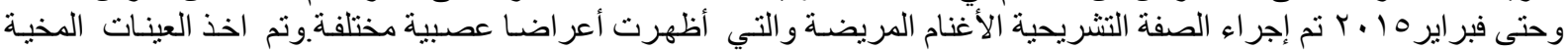

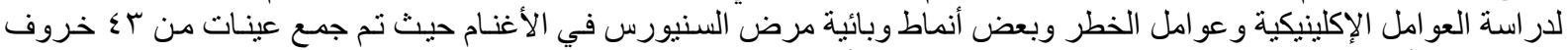

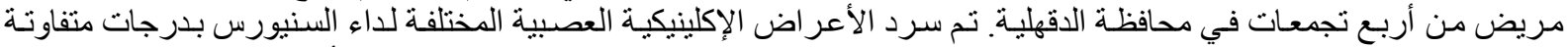

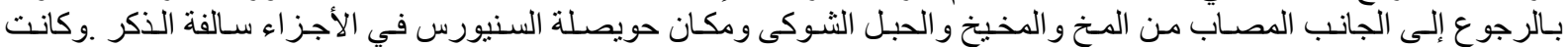

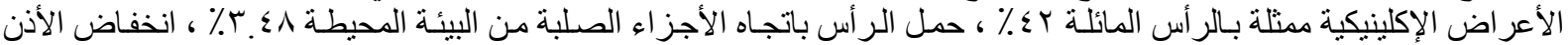

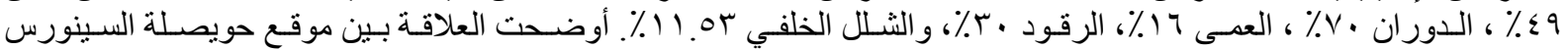

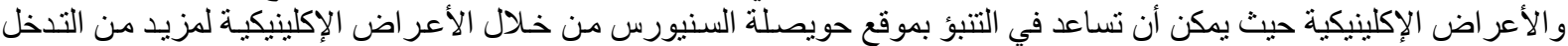

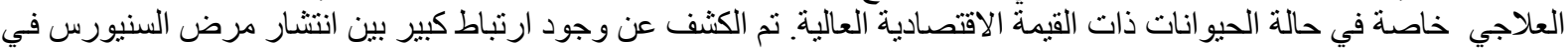

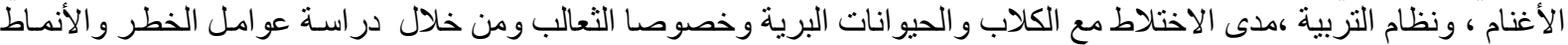
الوبائية لمرض السنيورس في الأغنام لكي نتمكن من إجراء تطوير تدابير السيطرة على المرض في المستقبل.
} 